\title{
Health effects of fine particulate matter in life cycle impact assessment: findings from the Basel Guidance Workshop
}

Fantke, Peter; Jolliet, Olivier; Evans, John S. ; Apte, Joshua S. ; Cohen, Aaron J. ; Hänninen, Otto O. ; Hurley, Fintan ; Jantunen, Matti J. ; Jerrett, Michael ; Levy, Jonathan I.

Total number of authors:

19

Published in:

International Journal of Life Cycle Assessment

Link to article, DOI:

$10.1007 / \mathrm{s} 11367-014-0822-2$

Publication date:

2015

Document Version

Peer reviewed version

Link back to DTU Orbit

Citation $(A P A)$ :

Fantke, P., Jolliet, O., Evans, J. S., Apte, J. S., Cohen, A. J., Hänninen, O. O., Hurley, F., Jantunen, M. J., Jerrett, M., Levy, J. I., Loh, M. M., Marshall, J.'D., Miller, B. G., Preiss, P., Spadaro, J. V., Tainio, M., Tuomisto, J. T., Weschler, C. J., \& McKone, T. E. (2015). Health effects of fine particulate matter in life cycle impact assessment: findings from the Basel Guidance Workshop. International Journal of Life Cycle Assessment, 20(2), 276-288. https://doi.org/10.1007/s11367-014-0822-2

\section{General rights}

Copyright and moral rights for the publications made accessible in the public portal are retained by the authors and/or other copyright owners and it is a condition of accessing publications that users recognise and abide by the legal requirements associated with these rights.

- Users may download and print one copy of any publication from the public portal for the purpose of private study or research.

- You may not further distribute the material or use it for any profit-making activity or commercial gain

- You may freely distribute the URL identifying the publication in the public portal 
1 Health Effects of Fine Particulate Matter in Life Cycle Impact Assessment:

2 Findings from the Basel Guidance Workshop

3 Peter Fantke ${ }^{1 \dagger}$, Olivier Jolliet ${ }^{2}$, John S. Evans ${ }^{3,4}$, Joshua S. Apte ${ }^{5^{*}}$, Aaron J. Cohen ${ }^{6 *}$, Otto O.

4 Hänninen $^{7^{*}}$, Fintan Hurley ${ }^{8^{*}}$, Matti J. Jantunen ${ }^{7^{*}}$, Michael Jerrett ${ }^{9^{*}}$, Jonathan I. Levy ${ }^{10^{*}}$,

5 Miranda M. Loh $^{11^{*}}$, Julian D. Marshall ${ }^{12^{*}}$, Brian G. Miller ${ }^{8^{*}}$, Philipp Preiss ${ }^{13^{*}}$, Joseph V.

6 Spadaro $^{14^{*}}$, Marko Tainio ${ }^{15,16^{*}}$, Jouni T. Tuomisto ${ }^{7^{*}}$, Charles J. Weschler ${ }^{17,18^{*}}$, Thomas E.

7 McKone $e^{9,19}$

${ }^{1}$ Quantitative Sustainability Assessment Division, Department of Management Engineering, Technical University of Denmark, Produktionstorvet 424, 2800 Kgs. Lyngby, Denmark

${ }^{2}$ School of Public Health, University of Michigan, Ann Arbor, MI 48109, USA

${ }^{3}$ Department of Environmental Health, Harvard School of Public Health, Boston, MA 02115, USA

${ }^{4}$ Cyprus International Institute for Environment and Public Health, Cyprus University of Technology,

143041 Limassol, Cyprus

${ }^{5}$ Energy and Resources Group, University of California, Berkeley, CA 94720, USA

${ }^{6}$ Health Effects Institute, Boston, MA 02110, USA

${ }^{7}$ National Institute for Health and Welfare, 70701 Kuopio, Finland

${ }^{8}$ Institute of Occupational Medicine, Edinburgh EH14 4AP, United Kingdom

${ }^{9}$ School of Public Health, University of California, Berkeley, CA 94720, USA

${ }^{10}$ School of Public Health, Boston University, Boston, MA 02118, USA

${ }^{11} \mathrm{Mel}$ and Enid Zuckerman College of Public Health, University of Arizona, Tucson, AZ 85724, USA

${ }^{12}$ Department of Civil Engineering, University of Minnesota, Minneapolis, MN 55455, USA

${ }^{13}$ econcept AG, 8002 Zurich, Switzerland

${ }^{14}$ Basque Centre for Climate Change, 48008 Bilbao Bizkaia, Spain

${ }^{15}$ Systems Research Institute, Polish Academy of Sciences, 01-447 Warsaw, Poland

${ }^{16}$ UKCRC Centre for Diet and Activity Research, University of Cambridge, United Kingdom

${ }^{17}$ Environmental and Occupational Health Sciences Institute, Rutgers University, Piscataway, NJ 08854, USA

${ }^{18}$ International Centre for Indoor Environment and Energy, Technical University of Denmark, 2800 Kgs. Lyngby, Denmark

${ }^{19}$ Lawrence Berkeley National Laboratory, Berkeley, CA 94720, USA

*Authors listed alphabetically. 


\section{Abstract}

Purpose Fine particulate matter $\left(\mathrm{PM}_{2.5}\right)$ is considered to be one of the most important environmental factors contributing to the global human disease burden. However, due to the lack of broad consensus and harmonization in the life cycle assessment (LCA) community, there is no clear guidance on how to consistently include health effects from $\mathrm{PM}_{2.5}$ exposure in LCA practice. As a consequence, different models are currently used to assess life cycle impacts for $\mathrm{PM}_{2.5}$, sometimes leading to inconsistent results. In a global effort initiated by the UNEP/SETAC Life Cycle Initiative, respiratory inorganics impacts expressed as health effects from $\mathrm{PM}_{2.5}$ exposure were selected as one of the initial impact categories to undergo review with the goal of providing global guidance for implementation in life cycle impact assessment (LCIA). The goal of this paper is to summarize the current knowledge and practice for assessing health effects from $\mathrm{PM}_{2.5}$ exposure and to provide recommendations for their consistent integration into LCIA.

Methods A task force on human health impacts was convened to build the framework for consistently quantifying health effects from $\mathrm{PM}_{2.5}$ exposure and for recommending $\mathrm{PM}_{2.5}$ characterization factors. In an initial Guidance Workshop, existing literature was reviewed and input from a broad range of internationally-recognized experts was obtained and discussed. Workshop objectives were to identify the main scientific questions and challenges for quantifying health effects from $\mathrm{PM}_{2.5}$ exposure, and to provide initial guidance to the impact quantification process.

Results and recommendations A set of 10 recommendations was developed addressing: (a) the general framework for assessing $\mathrm{PM}_{2.5}$-related health effects, (b) approaches and data to estimate human exposure to $\mathrm{PM}_{2.5}$ using intake fractions, and (c) approaches and data to characterize exposure-response functions (ERF) for $\mathrm{PM}_{2.5}$ and to quantify severity of the diseases attributed to $\mathrm{PM}_{2.5}$ exposure. Despite these advances, a number of complex issues, such as those related to non-linearity of the ERF and the possible need to provide different ERF's for use in different geographic regions, require further analysis.

Conclusions and outlook Questions of how to refine and improve the overall framework were analyzed. Data and models were proposed for harmonizing various elements of the health impact pathways for $\mathrm{PM}_{2.5}$. Within the next two years, our goal is to build a global guidance framework and to determine characterization factors that are more reliable for incorporating the health effects from exposure to $\mathrm{PM}_{2.5}$ into LCIA. Ideally, this will allow quantification of the impacts of both indoor and outdoor exposure to $\mathrm{PM}_{2.5}$. 


\section{$71 \quad$ Keywords}

72 fine particulate matter, air pollution, human health effects, intake fraction, exposure-response 73 function, global guidance, life cycle impact assessment (LCIA)

74 


\section{Health effects from fine particulate matter: Towards global guidance in life cycle} assessment

Life cycle assessment (LCA) is a structured, comprehensive, and internationally standardized method to assess potential environmental impacts and resources used throughout the life cycle of a good or service in a comparable way (ISO 2006). LCA thereby aims for best estimates in the modelling of all relevant impacts on the natural environment, human health, and resources in the life cycle impact assessment (LCIA) phase (EC 2010a, Finnveden et al. 2009). To help identify best LCA practice, Phase III (2012-2016) of the UNEP/SETAC Life Cycle Initiative ${ }^{1}$ has launched a flagship project aiming to provide global guidance and consensus on a limited number of LCIA indicators. The Glasgow Scoping Workshop in May 2013 (Jolliet et al. 2014) focused on establishing a tentative short list of impact category indicators that would be addressed during two consensus building periods. These indicators included the impacts of respiratory inorganics expressed as health effects from exposure to primary and secondary particulate matter (PM), which is considered to be one of the most important environmental stressors contributing to the global human disease burden (Hänninen et al. 2014, Lim et al. 2012). Primary PM refers to directly emitted particles. Secondary PM refers to organic and inorganic (e.g. ammonium nitrate, ammonium sulfate) particles formed through reactions of precursor substances including nitrogen oxides $\left(\mathrm{NO}_{\mathrm{x}}\right)$, sulfur oxides $\left(\mathrm{SO}_{\mathrm{x}}\right)$, ammonia $\left(\mathrm{NH}_{3}\right)$, semivolatile and volatile organic compounds (VOC), of which the latter are most important for secondary organic aerosol formation. PM is further distinguished according to aerodynamic diameter, i.e. respirable particles $\left(\mathrm{PM}_{10}\right)$ with $<10 \mu \mathrm{m}$, fine particles $\left(\mathrm{PM}_{2.5}\right)$ with $<2.5 \mu \mathrm{m}$, and ultrafine particles (UFP) with $<100 \mathrm{~nm}$ aerodynamic diameter (WHO 2006). $\mathrm{PM}_{2.5}$ was chosen to provide international recommendations regarding the consistent integration of its health effects into LCIA because it might best describe the component of particulate matter responsible for adverse health effects (Harrison \& Yin 2000, Lim et al. 2012, Lippmann \& Chen 2009).

\section{Assessing fine particulate matter in the context of life cycle impact assessment}

In epidemiological studies, exposure to $\mathrm{PM}_{2.5}$ is associated with various adverse health effects and reduction in life expectancy including chronic and acute respiratory and cardiovascular morbidity, chronic and acute mortality, lung cancer, diabetes, and adverse birth outcomes (Beelen et al. 2014, Brook et al. 2010, Chen et al. 2008, COMEAP 2010, Dadvand et al. 2013, Hoek et al. 2013, Künzli et al. 2000, Lippmann \& Chen 2009, Loomis et al. 2013,

\footnotetext{
${ }^{1}$ http://www.lifecycleinitiative.org/activities/phase-iii
} 
Mehta et al. 2013, Pelucchi et al. 2009, Pope III et al. 2009, Pope III et al. 2011, Straif et al. 2013). Furthermore, toxicological studies support the observation that exposure to $\mathrm{PM}_{2.5}$ can exert effects on key biological systems, with some evidence that not all particles are likely to cause the same health effects (Harrison \& Yin 2000, Kelly \& Fussell 2012, Rohr \& Wyzga 2012, Stanek et al. 2011). Several existing LCIA methods already characterize health effects associated with ambient PM or $\mathrm{PM}_{2.5}$ concentrations (EC 2010c), mostly based on ambient $\mathrm{PM}_{2.5}$ intake estimated from simple exposure or intake fraction models and using health effect data from the Harvard Six Cities and American Cancer Society studies (Krewski et al. 2000, Laden et al. 2006, Pope III et al. 2002). A few studies include spatial allocation of emissions and modeling of air dispersion and chemical reactions to predict downwind $\mathrm{PM}_{2.5}$ concentrations (Hill et al. 2009, Tessum et al. 2012). Whenever emission locations are known, these spatially-explicit approaches can be applied in LCIA. It is anticipated in the future to fully assess $\mathrm{PM}_{2.5}$ impacts using such spatially explicit approaches. In the current absence of this capacity, a consistent and globally harmonized approach for LCIA should be based on the most recent science to simultaneously address environmental fate, human exposure, and health effects of $\mathrm{PM}_{2.5}$ concentrations resulting from emissions of primary $\mathrm{PM}_{2.5}$ and secondary $\mathrm{PM}_{2.5}$ precursors (Hauschild et al. 2013).

One of the challenges in LCA is that impacts are linked to emissions via intake, whereas in epidemiology, impacts are related to concentrations. Generally, when assessing the health response of a population, the most accurate and efficient approach is to relate observed concentrations to population response. This also constitutes the basis for the LCA framework. However, this approach needs to be adapted for the emission-based LCA context for which the impact of an additional $\mathrm{kg}$ emitted by multiple sources in different, often unknown locations needs to be evaluated (Finnveden et al. 2009, Hauschild 2005). For such emissionbased assessments, the human intake fraction (iF) as the fraction of an emitted mass ultimately taken in by the total exposed population is well adapted, accounting directly for a temporally and spatially integrated concentration multiplied by nominal human intake rates. Intake fraction is a time- and space-integrated metric, easy to understand, to communicate and to combine with chemical emissions. Emission source types can be associated with specific $\mathrm{iF}$, which is easier to interface and combine at the level of exposure than a field of concentrations over a certain distance around the source.

With respect to assessing the particular health effects from $\mathrm{PM}_{2.5}$ exposure, the effort of an earlier UNEP/SETAC working group has designed a framework and proposed a set of

141 default iF associated with $\mathrm{PM}_{2.5}$ emissions for use in LCIA (Humbert et al. 2011). This effort 
142 is limited to the steps of the impact pathway from emissions to concentration and human

143 intake, but does not cover the steps from human intake to health effects. In addition, due to

144 the lack of broad consensus and harmonization in the LCA community, there is no clear

145 guidance on how to include health effects from $\mathrm{PM}_{2.5}$ exposure in LCA practice. As a

146 consequence, different models are currently used leading at times to inconsistent life cycle

147 impact results reported for this category. This reveals the importance of pursuing consensus

148 building, based on the initial work of Humbert et al. (2011) and combining it with latest

149 exposure-response and severity data to yield revised guidance on the development and use of

150 human health characterization factors for both primary and secondary $\mathrm{PM}_{2.5}$ including

151 precursor substances. Ultrafine particles are currently not separately considered in LCA.

152 To meet our needs for global guidance and harmonization regarding health effects from

$153 \mathrm{PM}_{2.5}$ exposure in LCIA, the UNEP/SETAC Life Cycle Initiative established a task force on

154 human health impacts. The aim of the task force is to build within the next two years a

155 framework and determine factors recommended for incorporating human health effects from

$156 \mathrm{PM}_{2.5}$ exposure into LCIA and addressing both outdoor and indoor releases. In order to

157 provide a starting point for the task force effort, the workshop participants summarize in this

158 paper the current knowledge on and practice in assessing the health effects from $\mathrm{PM}_{2.5}$

159 exposure including related recommendations.

160

1613 The Basel Guidance Workshop: Identifying and addressing the key questions

162 Within the task force on human health impacts, an initial Guidance Workshop was 163 organized back-to-back with the ISEE/ISES/ISIAQ Environment and Health Conference in

164 Basel, Switzerland, in August 2013. Based on a literature review and expert input, the workshop organizers reached out to a broad range of internationally recognized experts in PM exposure and health effects. Sixteen of these experts agreed both to participate in the process and attend the Basel workshop (in person or by phone). This included experts from Canada, Denmark, Finland, Germany, Poland, Spain, Switzerland, the United Kingdom, and the United States. Many others have agreed to contribute in some form to the task force activities.

The specific objectives of the workshop were to first identify and discuss the main scientific questions and challenges for quantifying human health effects from $\mathrm{PM}_{2.5}$ exposure, and then to provide initial guidance to the impact quantification process. Three main topics were addressed at the workshop: (a) the general assessment framework as proposed by

174 Humbert et al. (2011), (b) approaches and data to determine human exposure to $\mathrm{PM}_{2.5}$

175 expressed as intake fractions, and (c) approaches and data to determine exposure-response 
functions (ERF) for $\mathrm{PM}_{2.5}$ along with disease severity. For these topics, the workshop participants discussed a set of key questions that had been established with selected experts in three pre-workshop phone conferences. Table 1 summarizes these key questions, which are discussed in detail in the following.

Table 1 Key questions discussed during the Basel Guidance Workshop

\section{General assessment framework}

- Can we use the framework that is proposed in Figure 1 based on work from Humbert et al. (2011) to include health effects from respiration of ambient particulate matter into life cycle impact assessment?

\section{Human intake fraction}

- What additional factors/aspects will we have to take into account, i.e. those that substantially influence intake fractions by at least a factor of two?

- Can we use archetypes to disaggregate aspects influencing intake fractions (emission stack height, primary/secondary particulates, particle size, and urban/rural/remote area) and what archetypal structure is meaningful?

- What is the added value of applying archetypes for emission sources (e.g. road transport) or specific regions (e.g. China)?

- How do we arrive at a consistent set of emission-weighted average intake fractions?

- Which existing studies, methods, and models are best or most usefully suited as starting points for arriving at a consistent set of intake fractions to improve factors stated in Humbert et al. (2011)?

- How can we properly address in life cycle impact assessment the combined environmental fate aspects of ammonia, nitrogen oxides, and sulfur oxides?

\section{Exposure-response functions and effect evaluation}

- What are the major studies that we need to take into account to determine exposureresponse functions for relevant health effects?

- In addition to cardiovascular diseases and lung cancer, is it relevant to include other health effects, such as bronchitis or asthma in children?

- To what extent are exposure-response functions available for the fraction of particulates with an aerodynamic diameter below $2.5 \mu \mathrm{m}$ and what alternative approach would be applicable?

- Are there any emerging studies that would challenge our default approach?

- Are there studies providing evidence and specific exposure-response functions for differentiated effects for primary and secondary particulates?

- What relevant exposure studies are available for exposure to particulates from indoor sources and for outdoor particulates emissions in different parts of the world?

- How far can studies focusing on the United States (or studies mentioned under the first question of point 3) be applied as a default for different parts of the world or for indoor exposure to particulates?

- How can we consistently account for the severity of different (mortality and morbidity) health effects based on disability weights?

- How can damage measures be suggested in order of priority in terms of health effects?

4. Additional remarks

- What additional comments or recommendations could improve the set of intake 


\section{General assessment framework recommendations}

An overall picture of the approach currently proposed for health effects attributed to $\mathrm{PM}_{2.5}$ exposure in LCIA including the findings of the Basel guidance workshop is presented in Figure 1.

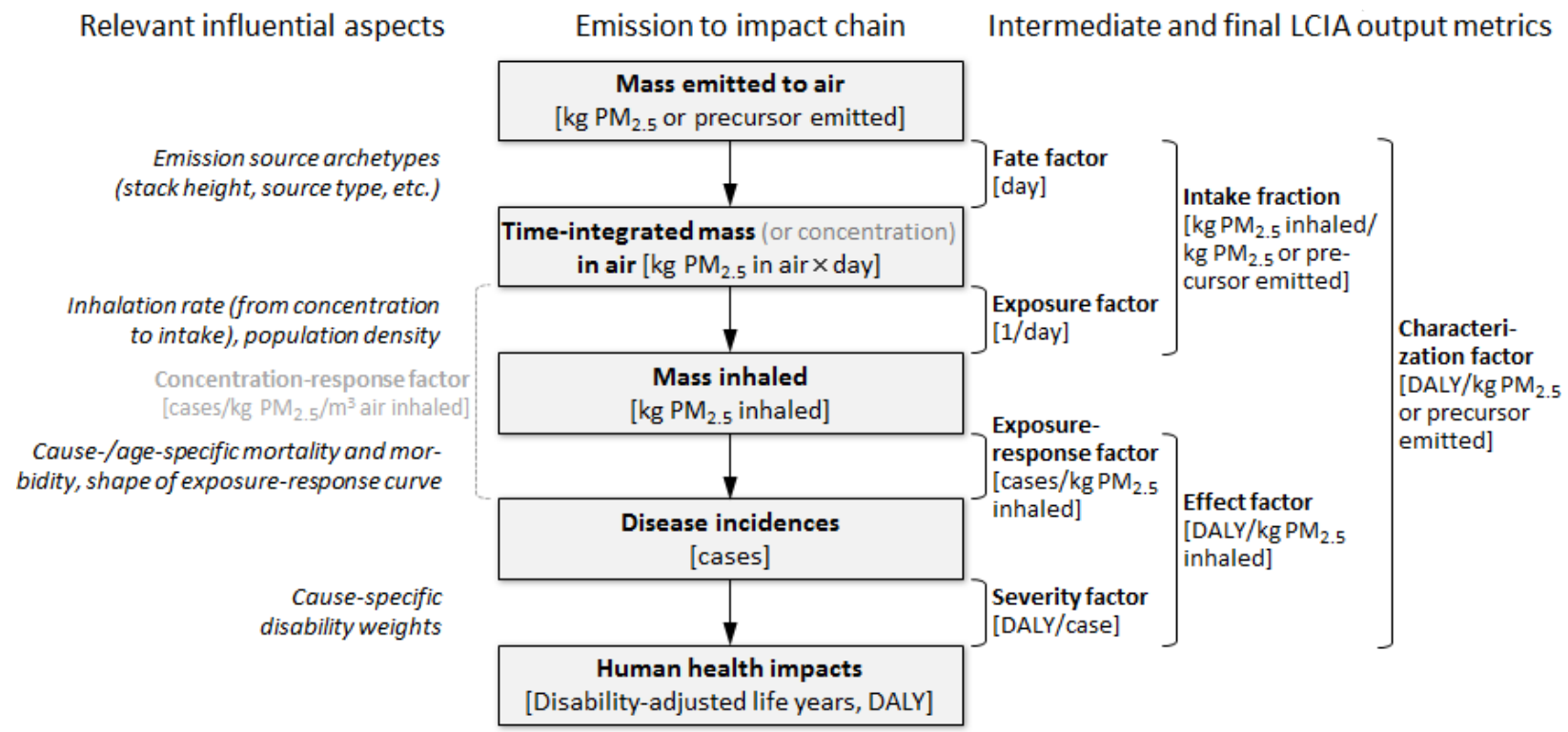

Figure 1 Proposed framework for assessing human health effects from fine particulate matter exposure in life cycle impact assessment; adapted from Humbert et al. (2011).

4.1 Overall assessment approach

There was agreement among the workshop participants to build upon the general framework proposed by Humbert et al. (2011). In this framework, human intake fractions for primary and secondary $\mathrm{PM}_{2.5}$ are provided, emissions from low and high stacks are differentiated, and dominant influences for generic landscape characteristics are parameterized. Humbert et al. (2011) thereby start from emissions of primary $\mathrm{PM}_{2.5}$ and secondary $\mathrm{PM}_{2.5}$ precursors into the environment, $\mathrm{m}$ (mass emitted), and multiply these emissions with intake fractions, $\mathrm{iF}$ (mass of $\mathrm{PM}_{2.5}$ inhaled by the affected population per mass of primary $\mathrm{PM}_{2.5}$ or secondary $\mathrm{PM}_{2.5}$ precursor emitted, respectively), an exposure-response factor derived from epidemiological studies linking health effects in the affected population to ambient $\mathrm{PM}_{2.5}$ concentrations, ${ }^{2} \mathrm{ERF}$ (disease rate per unit mass concentration), and a severity

\footnotetext{
${ }^{2} \mathrm{PM}_{2.5}$ concentrations can be converted to intake using the breathing rate of the exposed population. How to average the breathing rate for different activities, age, etc. remains to be further discussed.
} 
factor, SF (disability-adjusted life years, DALY per disease case), to arrive at a human health204 related impact score, IS (DALY):

$$
\mathrm{IS}=\mathrm{m} \times \underbrace{\mathrm{iF} \times \mathrm{ERF} \times \mathrm{SF}}_{\mathrm{CF}}
$$

Intake fraction, exposure-response factor and severity factor can be represented by the characterization factor, CF (DALY per mass emitted). A key assumption implicit in this framework is the linear, no-threshold ERF. While not uncontroversial, this assumption reflects current practice and recent recommendations in LCIA (EC 2010b, Potting et al. 2007), and is also applied in other studies as discussed e.g. in COMEAP (2009).

\subsection{Exposure metrics}

Two exposure metrics, (i) ambient $\mathrm{PM}_{2.5}$ concentration, and (ii) population intake of $\mathrm{PM}_{2.5}$, were considered as possible starting points for assessing health impacts from $\mathrm{PM}_{2.5}$ exposure. It should be noted that, when all populations are assigned the same population breathing rate, the exposure expressed as either ambient concentration or intake fraction are exactly proportional. In other LCIA areas, health impacts are typically assessed using population intake as exposure metric (Udo de Haes et al. 2002). This approach can be justified for many endpoints, e.g. cancer risk assessment for genetic carcinogens, where risk is proportional to cumulative intake (often expressed as applied dose), i.e. where there are no population thresholds and no appreciable non-linearities in the relationship between intake and response. However, in cases where there are thresholds, i.e. concentrations or intakes below which health effects are not induced even in the most sensitive individuals, or significant nonlinearities in describing response as a function of concentration or cumulative intake, this simple approach may not provide a satisfactory representation of the effect of changes in exposure on population health risk. To make the approach more appropriate in such cases, the population intake fraction can be used as a measure of the population's ambient $\mathrm{PM}_{2.5}$ exposure. For population exposure to $\mathrm{PM}_{2.5}$, it is reasonable to assume no threshold, but there are possibilities for non-linear response for highly exposed populations (Burnett et al. 2014).

Epidemiological studies of the health impacts of exposure to $\mathrm{PM}_{2.5}$ typically report the relative risk of morbidity or mortality (i.e., the ratio of the risk among the exposed to that among the unexposed) as a function of the concentration of $\mathrm{PM}_{2.5}$ measured at fixed site monitors (see, for example, COMEAP 2010). They are not based on concentrations found through personal exposure monitoring (Hurley et al. 2005). In LCIA, the impact of an additional $\mathrm{kg}$ often emitted by multiple sources at different, often unknown locations over the life cycle is evaluated, making it effectively impossible to report the related concentrations. 
Recognizing the need for a population-scale exposure metric often without access to sitespecific emissions data, workshop participants recommended the use of population intake fraction, which is equivalent to population exposure concentration, as the default measure for computing $\mathrm{PM}_{2.5}$ health risks in LCIA. Population intake estimates computed using iF reflect the change in population-weighted intake of the ambient outdoor concentration. Thus, intake estimates are directly related to concentrations underlying epidemiological estimates of mortality and morbidity risks from $\mathrm{PM}_{2.5}$ exposure, although this requires knowledge about background concentrations when using non-linear exposure-response functions.

\subsection{Health metrics}

Various health metrics were discussed, including total and premature mortality, years of life lost (YLL), and disability-adjusted life years (DALY). Most workshop participants felt that when death is the outcome of interest, YLL is a better measure of mortality impacts than numbers of deaths. The view was that information on the number of deaths is more challenging to interpret because reduced $\mathrm{PM}_{2.5}$ intake cannot affect the fact of death, but only its cause and timing (Leksell \& Rabl 2001, Rabl 2005). When it is necessary to combine mortality and morbidity impacts into a single summary measure, two approaches can be used. The first approach is to use DALY combining YLL and years lived with a disability (YLD) weighted by the quality of life during the period of disability (Murray \& Lopez 1996b, Murray \& Lopez 1996a). The second approach, which is frequently preferred by economists, is to use weights reflecting societal willingness to pay to avoid small incremental risks of mortality and morbidity.

The workshop participants see no reason to reconsider this matter. In summary, YLL and DALY seem to be appropriate health metrics for use in LCIA, since they focus attention on actions with the greatest potential to lead to improvement in the number of healthy life years lived by the exposed populations (Wang et al. 2012). In addition, selecting a preferred approach is an issue that affects all analyses of health impacts in LCIA. Typically, LCIA has relied on the DALY metric (EC 2010b) without age-weighting and/or discounting.

\subsection{Other framework discussion points}

Two additional aspects were briefly discussed at the workshop: (i) whether and, if so, how to address the dynamics when expressing of health impacts attributable to $\mathrm{PM}_{2.5}$ exposure, and (ii) how to account for differences between average and marginal impacts on health of primary and secondary $\mathrm{PM}_{2.5}$ precursor emissions, which may occur when either 
emissions-exposure or exposure-response functions exhibit thresholds or significant nonlinearities. The workshop participants agreed that in the long-term both issues require further attention.

\section{From emissions to concentration and human intake: Determining intake fractions}

\subsection{Archetypes structure}

In LCIA, it is common practice to make use of archetypal exposure scenarios, e.g. urban vs. rural scenarios (Riley et al. 2002), rather than site-specific exposure assessments, especially when emission locations are unknown. The workshop discussion focused on identifying the key factors influencing $\mathrm{iF}$ and determining how to address these in the context of quantifying $\mathrm{PM}_{2.5}$-related health effects in LCIA. Table 3 in Humbert et al. (2011) proposed one such archetypal structure in which population density (urban, rural, remote) and emission height (high-stack, low-stack, ground-level) serve as the main determinants of iF. Humbert et al. also provided a default set of $\mathrm{iF}$ values corresponding to these archetypes.

Workshop participants agreed to adopt this structure as starting point, but pointed out that additional refinements in terms of archetypes need to be explored. Refinements can thereby build on applying a sensitivity analysis to a range of aspects that influence the variability of $\mathrm{iF}$. This includes, for example, distinct urban areas based on work by Apte et al. (2012) and different emission sources, such as traffic-related sources (Greco et al. 2007, Lobscheid et al. 2012, Marshall et al. 2005), stationary emissions from coal/gas-fired power plants (Heath et al. 2006, Levy et al. 2003, Levy et al. 2002), or indoor emissions from wood burning (Ries et al. 2009). The participants also agreed to include additional archetypes reflecting exposure from indoor emissions of $\mathrm{PM}_{2.5}$ based on work by Hellweg et al. (2009).

\subsection{Geographical differentiation}

Despite the availability of studies that examine the influence of geographical location and spatial resolution on $\mathrm{PM}_{2.5}$ concentrations and exposures (Kheirbek et al. 2013, Zhou et al. 2006), questions remain about the level of geographical differentiation appropriate for LCIA and about how to properly characterize in LCIA the effects of differences in population age structure and disease incidence rates. Both issues appear to require further discussion. Based on that, workshop participants agreed that it would be useful to develop regional and/or continental sets of archetype-based iF to account for differences in environmental conditions (e.g. climate, precipitation, background concentration of secondary $\mathrm{PM}_{2.5}$ precursors), 
exposure conditions (e.g. population density, stack height), and receptor attributes (e.g. population age structure, disease incidence rates).

To account for differences in spatial scales, workshop participants suggested developing LCIA methods that differentiate between near-field (e.g. occupational settings; within $10 \mathrm{~m}$ ), neighborhood (scale of a block; order of $100 \mathrm{~m}$ ), urban (cities; order of 10-100 km), regional (order of 100-1,000 km), and continental scales (up to 10,000 km), thereby refining the archetypes used in Humbert et al. (2011).

Workshop participants also discussed the complex interactions between emissions of $\mathrm{NH}_{3}, \mathrm{NO}_{\mathrm{x}}$ and $\mathrm{SO}_{\mathrm{x}}$ with respect to the formation and intake of secondary nitrates and sulfates. At the regional-continental scale, in areas with little agriculture and significant industrial activity (for example, along the east coast of the US), emissions of $\mathrm{NH}_{3}$ are a limiting factor for secondary $\mathrm{PM}_{2.5}$ formation, whereas in rural areas dominated by agriculture, $\mathrm{NO}_{\mathrm{x}}$ and $\mathrm{SO}_{\mathrm{x}}$ are more commonly the factors limiting the formation of secondary $\mathrm{PM}_{2.5}$ (Paulot \& Jacob 2014, Squizzato et al. 2013, Xu \& Penner 2012). It was noted that geographically-resolved data for primary $\mathrm{PM}_{2.5}$ and secondary $\mathrm{PM}_{2.5}$ precursor emissions and $\mathrm{iF}$ for different emission heights are available for some regions (Apte et al. 2012, Levy et al. 2002, Pregger \& Friedrich 2009), but are not consistently available at the global level. It was agreed that in any attempt to differentiate geographic regions, particulate matter type (primary vs. secondary) is an important aspect to consider - secondary $\mathrm{PM}_{2.5} \mathrm{iF}$ are less sensitive than primary $\mathrm{PM}_{2.5} \mathrm{iF}$ to near source environmental, exposure and receptor characteristics (Humbert et al. 2011, Levy et al. 2003).

\subsection{Aggregation of intake fractions}

When combining iF from multiple sources, the appropriate approach is to multiply each emission's iF by the magnitude of that emission, sum this product for all emissions being combined and then divide by the total emissions to obtain the emissions-weighted iF for all the individual emissions that are linked by their association with a given functional unit in an LCA. In cases where emissions are not well characterized, it can be assumed that emissions (e.g. from vehicles or energy production) are proportional to population (Humbert et al. 2011). Population-weighted iF have been used in some studies as a proxy for emissionweighted iF (Apte et al. 2012, Humbert et al. 2009), but other source- or sector-specific emission-weights exist to account for spatial correlations between source locations and population patterns (Levy et al. 2002, Lobscheid et al. 2012). 
For all cases where the region, emission sources and locations, and/or population exposure conditions are unknown, it was agreed to use an emission-weighted average iF (i.e., site-generic) in the context of LCIA, as population intake is the result of multiplying iF by the corresponding emissions. To arrive at such emission-weights, the workshop participants suggested that the iF of each region/area (e.g. Indochina, Scandinavia) should be weighted according to the proportion of the contribution of this region to the total emission in the considered geographical domain (typically continental or global scale). This approach would be entirely consistent with previous efforts to develop iF values intended to be used to quantify the impact of $\mathrm{PM}_{2.5}$ or $\mathrm{PM}_{2.5}$ precursor emissions on ambient $\mathrm{PM}_{2.5}$ concentrations (Humbert et al. 2011, Levy et al. 2003, Marshall et al. 2003, Tainio et al. 2009).

\section{From concentration and human intake to health effects: Defining appropriate exposure-response functions}

\subsection{Effect assessment starting point}

In LCIA, ERF link estimates of population exposure with estimates of health effects. Whereas some guidance is available on deriving $\mathrm{PM}_{2.5}$ intake fractions for use in LCIA (Humbert et al. 2011), guidance has not yet been established on the development of $\mathrm{PM}_{2.5}$ exposure-response to support LCIA.

Workshop participants agreed that models developed in support of the Global Burden of Disease Study (GBD) 2010 (Lim et al. 2012) may provide a reasonable framework for calculating health effects of $\mathrm{PM}_{2.5}$ exposure. GBD 2010 provides estimates of the health effects (expressed in DALY) caused by 67 risk factors for both 1990 and 2010. GBD estimates are provided for each of 21 world regions (based on epidemiological homogeneity and geographical contiguity) and are disaggregated by age (20 groups) and sex. $\mathrm{PM}_{2.5}$ as one of the considered risk factors was associated with five adverse health effects - ischemic heart disease, cerebrovascular disease, cancers of the trachea/bronchus or lung, chronic obstructive pulmonary disease among adults ( $\geq 25$ years old), and lower respiratory infections among young children ( $\leq 5$ years old). For these effects, risk estimates were developed using an integrated exposure-response (IER) function which provided cause-specific estimates of the relative risk as a function of the ambient $\mathrm{PM}_{2.5}$ concentration over a broad range of exposures from the counterfactual or threshold level to concentrations on the order of $100 \mu \mathrm{g} / \mathrm{m}^{3}$ (Burnett et al. 2014). This model was labelled "integrated" because it combined evidence from studies of the health effects of ambient $\mathrm{PM}_{2.5}$ with studies of the effects of active and 
passive smoking. Other health effects were not considered, because epidemiological evidence was either inconclusive or absent.

GBD 2010 not only computes the relative risks of various health effects as a function of ambient $\mathrm{PM}_{2.5}$ concentrations, but also assigns DALY to each of the five health outcomes studied. In their 2010 analysis, GBD uses DALY that (a) are neither age-weighted nor discounted, (b) were derived using a counterfactual life expectancy at birth of 86 years for both males and females derived from the lowest age-specific death rates observed in any country (Murray et al. 2012), and (c) using disability weights derived from population-based household surveys involving 13,902 participants from Bangladesh, Indonesia, Peru, South Africa, Tanzania and the United States and an internet-based survey of 16,328 participants from 167 countries, 44\% of whom were from the United States (Salomon et al. 2012). The approach applied in GBD 2010 to derive DALY that are not age-weighted or discounted, is consistent with current LCIA practice (EC 2010c).

In summary, workshop participants consider the GBD 2010 models for the relative risks of the five health effects as a function of ambient $\mathrm{PM}_{2.5}$ concentrations as suitable starting points for developing ERF for use in LCIA. Because $\mathrm{PM}_{2.5}$ exposures associated with LCA applications and populations differ from those addressed in the GBD study, the question of whether the GBD 2010 disability weights for PM $_{2.5}$ are well-suited to directly apply in LCIA requires further discussion. Currently, the workshop participants consider the GBD 2010 disability weights a useful starting point.

\subsection{Health effects}

Health effects associated with $\mathrm{PM}_{2.5}$ exposure include a wide range of diseases. To date, PM exposure-response functions used in LCIA have focused on chronic and acute mortality and acute respiratory and cardiovascular morbidity associated with exposure to $\mathrm{PM}_{10}$ (van Zelm et al. 2008) or on cardiopulmonary mortality and lung cancer attributable to chronic exposure to $\mathrm{PM}_{2.5}$ (Gronlund et al. 2014). ERF have been derived using several approaches discussed in EC (2010c), primarily based on results from the Harvard Six Cities and American Cancer Society studies (Krewski et al. 2000, Laden et al. 2006, Pope III et al. 2002). Although the impact of $\mathrm{PM}_{2.5}$ exposure on asthma has been reported in several epidemiological studies (Brauer et al. 2002, Kheirbek et al. 2013, Künzli et al. 2000), asthma is usually not considered in LCIA. At the workshop, it was noted that evidence linking $\mathrm{PM}_{2.5}$ exposure with new asthma incidences is inconclusive, whereas it does support a link between $\mathrm{PM}_{2.5}$ exposure and the exacerbation of existing asthma (Donaldson et al. 2000, Gavett \& 
Koren 2001, Pope III et al. 1995). However, since it is unclear how to differentiate between induction of new cases and exacerbation of existing disease, there was no agreement on whether, and if so how, to include asthma as a health effect in LCIA.

It was emphasized that, in addition to the GBD 2010 effort, there is a large European movement to decide which health effects associated with $\mathrm{PM}_{2.5}$ exposure to quantify. This involves two projects ${ }^{3}$ - the Health Risks of Air Pollution in Europe, HRAPIE (WHO 2013a), and Review of Evidence on Health Aspects of Air Pollution, REVIHAAP (WHO 2013b). These projects aim to provide advice in support of the comprehensive review of European Union's air quality policies scheduled for 2013. A consensus document reflecting this effort was published end of 2013 (WHO 2013a). Whereas the GBD 2010 effort focuses on causespecific mortality, the HRAPIE/REVIHAAP projects recommend all-cause analysis as primary choice and cause-specific analysis as alternative method based on similarity of the frequency of the causes of death linked with exposure between considered cohorts and countries. It can be argued that a cause-specific assessment is particularly important in global assessments because of the large geographical variability in the relative importance of various causes of death. This view is supported by several studies (Lipsett et al. 2011, Miller et al. 2007, Puett et al. 2011, Puett et al. 2009).

Considering these different approaches, workshop participants agreed to recommend that LCIA should assess cause-specific mortality, when feasible, whereas all-cause mortality along with an appropriate assessment of uncertainty might still be useful in case of inconclusive allocation to causes. Furthermore, health effects considered in GBD 2010 and in the HRAPIE consensus document should serve as a starting point.

\subsection{Shape of exposure-response functions}

In current LCIA practice, the shape of population ERF is usually assumed to be linear with no threshold. This approach is supported by several studies which find no evidence of a departure from linearity (Chen et al. 2013, Schwartz et al. 2008, Stafoggia et al. 2013, WHO 2006) and no evidence suggesting a threshold at the population level (COMEAP 2009, 2010). Despite this, when these linear functions are applied to the very high $\mathrm{PM}_{2.5}$ levels often found in developing countries, the estimates of risk are so high as to be implausible (Abrahamowicz et al. 2003, EC 2010b). Recently, several research groups have suggested non-linear ERF that could be applied across a large range of $\mathrm{PM}_{2.5}$ concentrations, from very low to very high $\mathrm{PM}_{2.5}$ concentrations. These are typically steep at low concentration levels and relatively flat

\footnotetext{
${ }^{3}$ http://www.euro.who.int/en/what-we-do/health-topics/environment-and-health/air-quality/activities/healthaspects-of-air-pollution-and-review-of-eu-policies-the-revihaap-and-hrapie-projects
} 
at high levels (Abrahamowicz et al. 2003, Burnett et al. 2014, Ostro 2004, Pope III et al. 2009). Whether, and if so, how this approach can be adapted for use in LCIA needs to be further discussed, acknowledging that LCA aims to support decisions in regions with low concentration levels and also in regions with high concentration levels. From a sustainability point of view, intervention in highly polluted areas may be a priority despite the lower response per unit exposure. Significant departures from linearity would imply that iF would need to be reconstructed in a manner that is stratified by $\mathrm{PM}_{2.5}$ concentration or other relevant factors. In making such a change, it is also important to realize that the shape of the ERF might be effect-specific - for example nearly linear for lung cancer, but substantially nonlinear for cardiovascular mortality (Pope III et al. 2011). In GBD 2010, effect-specific, integrated ERF are proposed for $\mathrm{PM}_{2.5}$ (Lim et al. 2012). These ERF express relative risk as an exponential function (or a power function) of $\mathrm{PM}_{2.5}$ concentration (Burnett et al. 2014). In order to apply such non-linear ERF in LCIA, non-linear models can either be directly applied as e.g. in van Zelm et al. (2008) for ozone formation or be decomposed into piecewise linear functions. Workshop participants explained that methods for applying this approach are currently being developed.

In summary, it was agreed to further discuss how the ERF from GBD 2010 together with recommendations from the HRAPIE project can be adapted to serve as starting points. Thereby, workshop participants acknowledge that the slope of any linear ERF will vary as a function of different $\mathrm{PM}_{2.5}$ concentration ranges. LCIA methods will therefore need to be developed which can account for the variation in background levels of ambient $\mathrm{PM}_{2.5}$ around the world. This is challenging because in an LCA framework, the exact geographical locations of individual emission sources are typically unknown (Finnveden et al. 2009, Hauschild 2005, Humbert et al. 2011). Even if the source locations were known, the LCA analyst would need to integrate concentrations (and risks) over large areas, including individuals quite close to the source as well as those far from the source, to capture the entire exposed population. In principle, this can be addressed by treating the location of the emission source as uncertain and computing the distribution of possible impacts and recognizing this as a source of uncertainty in estimates of health impact.

\subsection{Particle characteristics and differential toxicity}

$\mathrm{PM}_{2.5}$ mass is commonly used as an indicator of the risk associated with exposure to a mixture of particle-related pollutants (of different sizes below $2.5 \mu \mathrm{m}$ diameter) from diverse (primary or secondary) sources and in different environments (COMEAP 2009, Lim et al. 
2012, Pope III et al. 2009, Pope III et al. 2011). This approach, which implicitly assumes equal toxicity of $\mathrm{PM}_{2.5}$ constituents per mass unit, is commonly used in LCIA (Potting et al. 2007). There is currently no scientific consensus on the relative toxicity of various constituents of $\mathrm{PM}_{2.5}$. This, however, does not suggest that all particle constituents are in fact equally toxic, but instead that the toxicological and epidemiological evidence of differential toxicity is inconclusive (Hurley et al. 2005). One study found differential toxicity of multiple particle constituents for short-term exposure effects on hospital admissions (Levy et al. 2012), but further research is required to address other health outcomes, long-term exposure, and other geographical settings (Rohr \& Wyzga 2012).

In view of this it was agreed to use $\mathrm{PM}_{2.5}$ mass as an indicator of exposure without differentiating between and among primary and secondary $\mathrm{PM}_{2.5}$ and without differentiating between different $\mathrm{PM}_{2.5}$ constituents in terms of toxicity for cause-specific chronic mortality effects. However, the workshop participants understood that given the current state of scientific uncertainty about this matter it would be important to develop an approach for characterizing the uncertainty of the toxicity of various constituents of $\mathrm{PM}_{2.5}$ which reflects the lack of knowledge about which constituents of $\mathrm{PM}_{2.5}$ are in fact responsible for the toxicity of the mixture.

Another aspect in the discussion of particle characteristics is particle size. Experimental studies suggest that health effects from exposure to the ultrafine particle (UFP) fraction differ from those of larger particles due to distinct deposition patterns in the lung and clearance mechanisms (Oberdörster et al. 2005). There is epidemiological and toxicological evidence for specific adverse respiratory and cardiovascular effects from exposure to UFP (Delfino et al. 2005, Weichenthal et al. 2007). However, the limited evidence currently available is inconsistent for short-term exposure and does not yet address the impacts of long-term exposure (Rückerl et al. 2011). Thus, it is not yet possible to determine how health effects associated with exposure to UFP differ from those associated with exposure to larger particles (HEI 2013). Moreover, there is only limited literature that would allow for calculating iF for UFP, which is generally characterized by particle number rather than particle mass.

As a result, workshop participants decided not to separately incorporate UFP into LCIA at present, but suggested that in the future a correction factor might be introduced to account for the distribution of particle sizes. 


\subsection{Conclusions}

Workshop participants discussed the questions shown in Table 1 in an effort to find ways to refine and improve the overall framework and to suggest data and models that could harmonize the analysis of health impacts from exposure to ambient particulate matter. This discussion constituted a first step towards developing recommendations for addressing the health effects from exposure associated with emissions of primary $\mathrm{PM}_{2.5}$ and secondary $\mathrm{PM}_{2.5}$ precursors in LCIA. A set of 10 recommendations reflecting the consensus of workshop participants are summarized as follows:

- The intake fraction framework proposed by Humbert et al. (2011) provides a useful starting point for assessing health effects of ambient PM in LCIA with a focus on $\mathrm{PM}_{2.5}$.

- Human intake fractions can be used to estimate emission-related population exposure. In conjunction with population-averaged breathing rates, intake fractions can be used to estimate intake from air concentrations.

- Disability-adjusted life years without age-weighting or discounting, which aggregate mortality and morbidity, can be used as a summary health metric.

- For most cases, where emission locations are unknown, exposure scenario archetypes provide a useful approach to account for factors, such as population density, emission height, and exposure to $\mathrm{PM}_{2.5}$ from indoor sources, which influence human intake fractions. The decision whether additional archetypes are necessary should be based on a sensitivity analysis that considers the importance of these additional factors in reducing uncertainty in exposure estimates. When the exact emission location is known, spatially explicit fate and transport models should be used.

- Geographical archetypes of intake fractions should be established for indoor, near-field, neighborhood, urban, regional, and continental scales. Geographical differentiation should be further discussed and analyzed with respect to scale and non-linear chemical processes in the formation of secondary $\mathrm{PM}_{2.5}$.

- Emission-weighted average intake fractions should be used in cases where the nature of the emission sources and/or exposure conditions is unclear.

- The Global Burden of Disease Study 2010 is considered to provide a useful starting point for developing exposure-response functions for assessing $\mathrm{PM}_{2.5}$-related health effects in

\section{LCIA.}


- Cause-specific mortality can provide a more informative basis for developing LCIA characterization factors than all-cause mortality. Assumptions for age- and cause-specific disability weights should be further discussed and analyzed.

- Non-linear exposure-response functions are recommended in the Global Burden of Disease Study 2010, whereas linear functions are used in the consensus document of the Health Risks of Air Pollution in Europe projects. There remains a need for discussion about whether, and if so, how to integrate non-linear (or piecewise linear) exposureresponse functions into LCIA.

- $\mathrm{PM}_{2.5}$ mass can be used as the indicator of the health risk associated with PM inhalation exposure in LCIA. There is no justification at this time to differentiate between different primary/secondary $\mathrm{PM}_{2.5}$ sources or between different $\mathrm{PM}_{2.5}$ particle sizes regarding toxicity. However, analyses should report the uncertainties inherent in any assumptions made about the relative toxicity of various types of particles.

\subsection{Next steps}

Within the next two years, the goals of the task force on human health impacts are to build a global guidance framework and to determine characterization factors for incorporating the health effects from exposure to $\mathrm{PM}_{2.5}$ in LCIA and for including both indoor and outdoor releases. As next steps towards these goals, the first set of recommendations from the Basel

554 Guidance Workshop will be taken. Open questions and unsolved problems will be further studied that were pointed out by workshop participants and the proposed framework will be refined based on best available data and methods. The harmonized framework and related results will finally be presented at a Pellston Technical Workshop ${ }^{4}$ in 2015.

\footnotetext{
${ }^{4}$ Pellston Workshops are preeminent workshops held by the SETAC, each of which brings together leading scientists from academia, business, and governments around the world and focuses on a relevant environmental topic with proceedings published as a peer-reviewed report, book or journal article compilation.
} 


\section{References}

559 Abrahamowicz M, Schopflocher T, Leffondré K, du Berger R, Krewski D (2003): Flexible

560 modeling of exposure-response relationship between long-term average levels of particulate air pollution and mortality in the American Cancer Society Study. J Toxicol Env Health 66, $1625-1654$

Apte JS, Bombrun E, Marshall JD, Nazaroff WW (2012): Global intraurban intake fractions for primary air pollutants from vehicles and other distributed sources. Environ Sci Technol 46, 3415-3423

Beelen R, Raaschou-Nielsen O, Stafoggia M, Andersen ZJ, Weinmayr G et al. (2014): Effects of long-term exposure to air pollution on natural-cause mortality: An analysis of 22 European cohorts within the multicentre ESCAPE project. Lancet 383, 785-795

Brauer M, Hoek G, Van Vliet P, Meliefste K, Fischer PH, Wijga A, Koopman LP, Neijens HJ, Gerritsen J, Kerkhof M, Heinrich J, Bellander T, Brunekreef B (2002): Air pollution from traffic and the development of respiratory infections and asthmatic and allergic symptoms in children. Am J Resp Crit Care 166, 1092-1098

Brook RD, Rajagopalan S, Pope III CA, Brook JR, Bhatnagar A, Diez-Roux AV, Holguin F, Hong Y, Luepker RV, Mittleman MA, Peters A, Siscovick D, Smith Jr SC, Whitsel L, Kaufman JD (2010): Particulate matter air pollution and cardiovascular disease: An update to the scientific statement from the American Heart Association. Circulation 121, 2331-2378

Burnett RT, Pope III CA, Ezzati M, Olives C, Lim SS et al. (2014): An integrated risk function for estimating the global burden of disease attributable to ambient fine particulate matter exposure. Environ Health Persp 122, 397-403

Chen H, Goldberg MS, Villeneuve PJ (2008): A systematic review of the relation between long-term exposure to ambient air pollution and chronic diseases. Rev Environ Health 23, 243-297

Chen H, Burnett RT, Kwong JC, Villeneuve PJ, Goldberg MS, Brook RD, van Donkelaar A, Jerrett M, Martin RV, Brook JR, Copes R (2013): Risk of incident diabetes in relation to long-term exposure to fine particulate matter in Ontario, Canada. Environ Health Persp 121, 804-810

COMEAP, 2009: Long-Term Exposure to Air Pollution: Effect on Mortality, Health Protection Agency for the Committee on the Medical Effects of Air Pollutants, London, UK

COMEAP, 2010: The Mortality Effects of Long-Term Exposure to Particulate Air Pollution in the United Kingdom, Health Protection Agency for the Committee on the Medical Effects of Air Pollutants, London, UK

Dadvand P, Parker J, Bell ML, Bonzini M, Brauer M et al. (2013): Maternal exposure to particulate air pollution and term birth weight: A multi-country evaluation of effect and heterogeneity. Environ Health Persp 121, 367-373

Delfino RJ, Sioutas C, Malik S (2005): Potential role of ultrafine particles in associations between airborne particle mass and cardiovascular health. Environ Health Persp 113, 934-946

Donaldson K, Gilmour MI, MacNee W (2000): Asthma and PM 10 . Resp Res 1, 12-15 
EC, 2010a: International Reference Life Cycle Data System (ILCD) Handbook: General guide for Life Cycle Assessment - Detailed guidance, 1st Ed. European Commission, Brussels

600 EC, 2010b: International Reference Life Cycle Data System (ILCD) Handbook: Framework 601 and requirements for LCIA models and indicators, 1st Ed. European Commission, Brussels

602 EC, 2010c: International Reference Life Cycle Data System (ILCD) Handbook: Analysis of 603 existing Environmental Impact Assessment methodologies for use in Life Cycle Assessment, 604 1st Ed. European Commission, Brussels

605 Finnveden G, Hauschild MZ, Ekvall T, Guinée J, Heijungs R, Hellweg S, Koehler A, 606 Pennington D, Suh S (2009): Recent developments in life cycle assessment. J Environ 607 Manage 91, 1-21 Gavett SH, Koren HS (2001): The role of particulate matter in exacerbation of atopic asthma. Int Arch Allergy Imm 124, 109-112

Greco SL, Wilson AM, Spengler JD, Levy JI (2007): Spatial patterns of mobile source particulate matter emissions-to-exposure relationships across the United States. Atmos 612 Environ 41, 1011-1025

613 Gronlund CJ, Humbert S, Shaked S, O’Neill MS, Jolliet O (2014): Characterizing the burden 614 of disease of particulate matter for life cycle impact assessment. Air Qual Atmos Health, 615 doi:10.1007/s11869-014-0283-6

616 Hänninen O, Knol AB, Jantunen M, Lim T-A, Conrad A, Rappolder M, Carrer P, Fanetti A617 C, Kim R, Buekers J, Torfs R, Iavarone I, Classen T, Hornberg C, Mekel OCL (2014):

618 Environmental burden of disease in Europe: Estimates for nine stressors in six countries.

619 Environ Health Persp 122, 439-446

620 Harrison RM, Yin J (2000): Particulate matter in the atmosphere: Which particle properties 621 are important for its effects on health? Sci Total Environ 249, 85-101

622 Hauschild MZ (2005): Assessing environmental impacts in a life-cycle perspective. Environ 623 Sci Technol 39, 81A-88A

624 Hauschild MZ, Goedkoop M, Guinée J, Heijungs R, Huijbregts M, Jolliet O, Margni M, De 625 Schryver A, Humbert S, Laurent A, Sala S, Pant R (2013): Identifying best existing practice 626 for characterization modeling in life cycle impact assessment. Int J Life Cycle Assess 18, 683$627 \quad 697$

628 Heath GA, Granvold PW, Hoats AS, W Nazaroff W (2006): Intake fraction assessment of the 629 air pollutant exposure implications of a shift toward distributed electricity generation. Atmos 630 Environ 40, 7164-7177

631 HEI, 2013: Understanding the Health Effects of Ambient Ultrafine Particles, Health Effects 632 Institute, Boston

633 Hellweg S, Demou E, Bruzzi R, Meijer A, Rosenbaum RK, Huijbregts MAJ, McKone TE 634 (2009): Integrating human indoor air pollutant exposure within life cycle impact assessment. 635 Environ Sci Technol 43, 1670-1679 

(2009): Climate change and health costs of air emissions from biofuels and gasoline. P Natl

638 Acad Sci 106, 2077-2082

639 Hoek G, Krishnan RM, Beelen R, Peters A, Ostro B, Brunekreef B, Kaufman JD (2013):

640 Long-term air pollution exposure and cardio-respiratory mortality: A review. Environ Health $641 \quad 12,43-57$

642 Humbert S, Manneh R, Shaked S, Wannaz C, Horvath A, Deschênes L, Jolliet O, Margni M 643 (2009): Assessing regional intake fractions in North America. Sci Total Environ 407, 4812$644 \quad 4820$

645 Humbert S, Marshall JD, Shaked S, Spadaro JV, Nishioka Y, Preiss P, McKone TE, Horvath 646 A, Jolliet O (2011): Intake fraction for particulate matter: Recommendations for life cycle 647 impact assessment. Environ Sci Technol 45, 4808-4816

648 Hurley F, Alistair Hunt, Cowie H, Holland M, Miller B, Pye S, Watkiss P 2005: Methodology 649 for the Cost-Benefit analysis for CAFE: Vol. 2: Health Impact Assessment, AEA Technology 650 Assessment, Oxon, UK

651 ISO, 2006: ISO 14040 International Standard. Environmental Management - Life Cycle 652 Assessment - Principles and Framework. International Organization for Standardization, 653 Geneva, Switzerland

654 Jolliet O, Frischknecht R, Bare J, Boulay A-M, Bulle C et al. (2014): Global guidance on 655 environmental life cycle impact assessment indicators: Findings of the scoping phase. Int $\mathbf{J}$ 656 Life Cycle Assess 19, 962-967

657 Kelly FJ, Fussell JC (2012): Size, source and chemical composition as determinants of 658 toxicity attributable to ambient particulate matter. Atmos Environ 60, 504-526

659 Kheirbek I, Wheeler K, Walters S, Kass D, Matte T (2013): $\mathrm{PM}_{2.5}$ and ozone health impacts 660 and disparities in New York City: Sensitivity to spatial and temporal resolution. Air Qual 661 Atmos Health 6, 473-486

662 Krewski D, Burnett RT, Goldberg MS, Hoover K, Siemiatycki J, Jerrett M, Abrahamowicz 663 M, White WH 2000: Reanalysis of the Harvard Six Cities Study and the American Cancer 664 Society Study of particulate air pollution and mortality, Health Effects Institute, Boston, MA

665 Künzli N, Kaiser R, Medina S, Studnicka M, Chanel O, Filliger P, Herry M, Horak F, 666 Puybonnieux-Texier V, Quénel P, Schneider J, Seethaler R, Vergnaud J-C, Sommer H 667 (2000): Public-health impact of outdoor and traffic-related air pollution: A European 668 assessment. Lancet 356, 795-801

669 Laden F, Schwartz J, Speizer FE, Dockery DW (2006): Reduction in fine particulate air 670 pollution and mortality. Am J Resp Crit Care 173, 667-672

671 Leksell I, Rabl A (2001): Air pollution and mortality: Quantification and valuation of years of 672 life lost. Risk Anal 21, 843-857

673 Levy JI, Wolff SK, Evans JS (2002): A regression-based approach for estimating primary and 674 secondary particulate matter intake fractions. Risk Anal 22, 895-904 
Levy JI, Wilson AM, Evans JS, Spengler JD (2003): Estimation of primary and secondary particulate matter intake fractions for power plants in Georgia. Environ Sci Technol 37, 55285536

Levy JI, Diez D, Dou Y, Barr CD, Dominici F (2012): A meta-analysis and multisite timeseries analysis of the differential toxicity of major fine particulate matter constituents. Epidemiology 175, 1091-1099

Lim SS, Vos T, Flaxman AD, Danaei G, Shibuya K et al. (2012): A comparative risk assessment of burden of disease and injury attributable to 67 risk factors and risk factor clusters in 21 regions, 1990 - 2010: A systematic analysis for the Global Burden of Disease Study 2010. Lancet 380, 2224-2260

Lippmann M, Chen L-C (2009): Health effects of concentrated ambient air particulate matter (CAPs) and its components. Cr Rev Toxicol 39, 865-913

Lipsett MJ, Ostro BD, Reynolds P, Goldberg D, Hertz A, Jerrett M, Smith DF, Garcia C, Chang ET, Bernstein L (2011): Long-term exposure to air pollution and cardiorespiratory disease in the California Teachers Study cohort. Am J Resp Crit Care 184, 828-835

Lobscheid AB, Nazaroff WW, Spears M, Horvath A, McKone TE (2012): Intake fractions of primary conserved air pollutants emitted from on-road vehicles in the United States. Atmos Environ 63, 298-305

Loomis D, Grosse Y, Lauby-Secretan B, Ghissassi FE, Bouvard V, Benbrahim-Tallaa L, Guha N, Baan R, Mattock H, Straif K (2013): The carcinogenicity of outdoor air pollution. Lancet Oncol 14, 1262-1263

Marshall JD, Riley WJ, McKone TE, Nazaroff WW (2003): Intake fraction of primary pollutants: motor vehicle emissions in the South Coast Air Basin. Atmos Environ 37, 34553468

Marshall JD, Teoh S-K, W. Nazaroff W (2005): Intake fraction of nonreactive vehicle emissions in US urban areas. Atmos Environ 39, 1363-1371

Mehta S, Shin H, Burnett R, North T, Cohen AJ (2013): Ambient particulate air pollution and acute lower respiratory infections: A systematic review and implications for estimating the global burden of disease. Air Qual Atmos Health 6, 69-83

Miller KA, Siscovick DS, Sheppard L, Shepherd K, Sullivan JH, Anderson GL, Kaufman JD (2007): Long-term exposure to air pollution and incidence of cardiovascular events in women. New Engl J Med 356, 447-458

Murray CJL, Lopez AD 1996a: The Global Burden of Disease: A comprehensive assessment of mortality and disability from diseases, injuries and risk factors in 1990 and projected to 2020, Harvard University Press, Cambridge, MA

Murray CJL, Lopez AD (1996b): Evidence-based health policy - Lessons from the Global Burden of Disease Study. Science 274, 740-743

Murray CJL, Ezzati M, Flaxman AD, Lim S, Lozano R, Michaud C, Naghavi M, Salomon JA, Shibuya K, Vos T, Wikler D, Lopez AD (2012): GBD 2010: Design, definitions, and metrics. Lancet 380, 2063-2066 
Oberdörster G, Oberdörster E, Oberdörster J (2005): Nanotoxicology: An emerging discipline evolving from studies of ultrafine particles. Environ Health Persp 113, 823-839

717 Ostro B 2004: Environmental Burden of Disease Series, No. 5. Outdoor air pollution:

718 Assessing the environmental burden of disease at national and local levels, World Health 719 Organization, Geneva, Switzerland

720 Paulot F, Jacob DJ (2014): Hidden cost of U.S. agricultural exports: Particulate matter from 721 ammonia emissions. Environ Sci Technol 48, 903-908

722

723
Pelucchi C, Negri E, Gallus S, Boffetta P, Tramacere I, La Vecchia C (2009): Long-term particulate matter exposure and mortality: A review of European epidemiological studies. BMC Public Health 9, 453-460

Pope III CA, Dockery DW, Schwartz J (1995): Review of epidemiological evidence of health effects of particulate air pollution. Inhal Toxicol 7, 1-18

Pope III CA, Burnett RT, Thun MJ, Calle EE, Krewski D, Ito K, Thurston GD (2002): Lung cancer, cardiopulmonary mortality, and long-term exposure to fine particulate air pollution. $\mathrm{J}$ Am Med Assoc 287, 1132-1141

Pope III CA, Burnett RT, Krewski D, Jerrett M, Shi Y, Calle EE, Thun MJ (2009): Cardiovascular mortality and exposure to airborne fine particulate matter and cigarette smoke: Shape of the exposure-response relationship. Circulation 120, 941-948

Pope III CA, Burnett RT, Turner MC, Cohen A, Krewski D, Jerrett M, Gapstur SM, Thun MJ (2011): Lung cancer and cardiovascular disease mortality Associated with ambient air pollution and cigarette smoke: Shape of the exposure-response relationships. Environ Health Persp 119, 1616-1621

Potting J, Preiss P, Seppälä J, Struijs J, Wiertz J, Blazek M, Heijungs R, Itsubo N, Masanet E, Nebel B, Nishioka Y, Payet J, Becaert V, Basset-Mens C, Jolliet O 2007: Current Practice in LCIA of Transboundary Impact Categories. Report of Task Force 4 on Transboundary Impacts. UNEP/SETAC Life Cycle Initiative

Pregger T, Friedrich R (2009): Effective pollutant emission heights for atmospheric transport modelling based on real-world information. Environ Pollut 157, 552-560

Puett RC, Hart JE, Yanosky JD, Paciorek C, Schwartz J, Suh H, Speizer FE, Laden F (2009): Chronic fine and coarse particulate exposure, mortality, and coronary heart disease in the Nurses' Health Study. Environ Health Persp 117, 1702-1706

Puett RC, Hart JE, Suh H, Mittleman M, Laden F (2011): Particulate matter exposures, mortality, and cardiovascular disease in the Health Professionals Follow-up Study. Environ Health Persp 119, 1130-1135

Rabl A (2005): Air pollution mortality: Harvesting and loss of life expectancy. J Toxicol Env Health, 68, 1175-1180

Ries FJ, Marshall JD, Brauer M (2009): Intake fraction of urban wood smoke. Environ Sci Technol 43, 4701-4706 
Riley WJ, McKone TE, Lai ACK, Nazaroff WW (2002): Indoor particulate matter of outdoor origin: Importance of size-dependent removal mechanisms. Environ Sci Technol 36, 200-207

Rohr AC, Wyzga RE (2012): Attributing health effects to individual particulate matter constituents. Atmos Environ 62, 130-152

Rückerl R, Schneider A, Breitner S, Cyrys J, Peters A (2011): Health effects of particulate air pollution: A review of epidemiological evidence. Inhal Toxicol 23, 555-592

Salomon JA, Vos T, Hogan DR, Gagnon M, Naghavi M et al. (2012): Common values in assessing health outcomes from disease and injury: Disability weights measurement study for the Global Burden of Disease Study 2010. Lancet 380, 2129-2143

Schwartz J, Coull B, Laden F, Ryan L (2008): The effect of dose and timing of dose on the association between airborne particles and survival. Enviorn Health Persp 116, 64-69

Squizzato S, Masiol M, Brunelli A, Pistollato S, Tarabotti E, Rampazzo G, Pavoni B (2013): Factors determining the formation of secondary inorganic aerosol: A case study in the Po Valley (Italy). Atmos Chem Phys 13, 1927-1939

Stafoggia M, Samoli E, Alessandrini E, Cadum E, Ostro B, Berti G, Faustini A, Jacquemin B, Linares C, Pascal M, Randi G, Ranzi A, Stivanello E, Forastiere F (2013): Short-term associations between fine and coarse particulate matter and hospitalizations in Southern Europe: Results from the MED-PARTICLES project. Environ Health Persp 121, 1026-1033

Stanek LW, Sacks JD, Dutton SJ, Dubois J-JB (2011): Attributing health effects to apportioned components and sources of particulate matter: An evaluation of collective results. Atmos Environ 45, 5655-5663

Straif K, Cohen A, Samet J (2013): Air Pollution and Cancer. IARC Scientific Publication No. 161. International Agency for Research on Cancer, Lyon Cedex, France

Tainio M, Sofiev M, Hujo M, Tuomisto JT, Loh M, Jantunen MJ, Karppinen A, Kangas L, Karvosenoja N, Kupiainen K, Porvari P, Kukkonen J (2009): Evaluation of the European population intake fractions for European and Finnish anthropogenic primary fine particulate matter emissions. Atmos Environ 43, 3052-3059

Tessum CW, Marshall JD, Hill JD (2012): A spatially and temporally explicit life cycle inventory of air pollutants from gasoline and ethanol in the United States. Environ Sci Technol 46, 11408-11417

Udo de Haes HA, Finnveden G, Goedkoop M, Hauschild MZ, Hertwich E, Hofstetter P, Jolliet O, Klöpffer W, Krewitt W, Lindeijer E, Müller-Wenk R, Olsen S, Pennington DW, Potting J, Steen B (2002): Life-cycle impact assessment: Striving towards best practice. SETAC Press, Pensacola, Florida, USA

van Zelm R, Huijbregts MAJ, den Hollander HA, van Jaarsveld HA, Sauter FJ, Struijs J, van Wijnen HJ, van de Meent D (2008): European characterization factors for human health damage of $\mathrm{PM}_{10}$ and ozone in life cycle impact assessment. Atmos Environ 42, 441-453

Wang H, Dwyer-Lindgren L, Lofgren KT, Rajaratnam JK, Marcus JR, Levin-Rector A, Levitz CE, Lopez AD, Murray CJL (2012): Age-specific and sex-specific mortality in 187 
countries, 1970-2010: A systematic analysis for the Global Burden of Disease Study 2010.

793 Lancet 380, 2071-2094

794 Weichenthal S, Dufresne A, Infante-Rivard C (2007): Indoor ultrafine particles and childhood 795 asthma: exploring a potential public health concern. Indoor Air 17, 81-91

796 WHO, 2006: Health risks of particulate matter from long-range transboundary air pollution,

797 World Health Organization, European Centre for Environment and Health, Bonn, Germany

798 WHO, 2013a: Health risks of air pollution in Europe - HRAPIE project Recommendations for 799 concentration-response functions for cost-benefit analysis of particulate matter, ozone and 800 nitrogen dioxide, World Health Organization, Geneva, Switzerland

801 WHO, 2013b: Review of evidence on health aspects of air pollution - REVIHAAP Project, 802 World Health Organization, Geneva, Switzerland

803 Xu L, Penner JE (2012): Global simulations of nitrate and ammonium aerosols and their 804 radiative effects. Atmos Chem Phys 12, 9479-9504

805 Zhou Y, Levy JI, Evans JS, Hammitt JK (2006): The influence of geographic location on 806 population exposure to emissions from power plants throughout China. Environ Int 32, 365$807 \quad 373$ 